\title{
Synergism between feremycorrhizal symbiosis and free-living diazotrophs leads to improved growth and nutrition of wheat under nitrogen deficiency conditions
}

\author{
Khalil Kariman $^{1} \cdot$ Benjamin Moreira-Grez ${ }^{1} \cdot$ Craig Scanlan $^{1,2,3} \cdot$ Saleh Rahimlou ${ }^{4} \cdot$ Gustavo Boitt $^{1} \cdot$ Zed Rengel $^{1}$
}

Received: 17 August 2021 / Revised: 15 December 2021 / Accepted: 22 December 2021 / Published online: 7 January 2022

(c) Crown 2022

\begin{abstract}
A controlled-environment study was conducted to explore possible synergistic interactions between the feremycorrhizal (FM) fungus Austroboletus occidentalis and soil free-living $\mathrm{N}_{2}$-fixing bacteria (diazotrophs). Wheat (Triticum aestivum) plants were grown under $\mathrm{N}$ deficiency conditions in a field soil without adding microbial inoculum (control: only containing soil indigenous microbes), or inoculated with a consortium containing four free-living diazotroph isolates (diazotrophs treatment), A. occidentalis inoculum (FM treatment), or both diazotrophs and A. occidentalis inoculums (dual treatment). After 7 weeks of growth, significantly greater shoot biomass was observed in plants inoculated with diazotrophs (by $25 \%$ ), A. occidentalis (by 101\%), and combined inoculums (by 106\%), compared to the non-inoculated control treatment. All inoculated plants also had higher shoot nutrient contents (including $\mathrm{N}, \mathrm{P}, \mathrm{K}, \mathrm{Mg}, \mathrm{Zn}, \mathrm{Cu}$, and $\mathrm{Mn}$ ) than the control treatment. Compared to the control and diazotrophs treatments, significantly greater shoot $\mathrm{N}$ content was observed in the FM treatment (i.e., synergism between the FM fungus and soil indigenous diazotrophs). Dually inoculated plants had the highest content of nutrients in shoots (e.g., N, P, K, S, Mg, Zn, Cu, and Mn) and soil total N (13-24\% higher than the other treatments), i.e., synergism between the FM fungus and added diazotrophs. Root colonization by soil indigenous arbuscular mycorrhizal fungi declined in all inoculated plants compared to control. Non-metric multidimensional scaling (NMDS) analysis of the bacterial 16S rRNA gene amplicons revealed that the FM fungus modified the soil microbiome. Our in vitro study indicated that A. occidentalis could not grow on substrates containing lignocellulosic materials or sucrose, but grew on media supplemented with hexoses such as glucose and fructose, indicating that the FM fungus has limited saprotrophic capacity similar to ectomycorrhizal fungi. The results revealed synergistic interactions between A. occidentalis and soil free-living diazotrophs, indicating a potential to boost microbial $\mathrm{N}_{2}$ fixation for non-legume crops.
\end{abstract}

Keywords Feremycorrhiza $\cdot$ Austroboletus occidentalis $\cdot$ Nitrogen fixation $\cdot$ Diazotrophs $\cdot$ Synergism

\section{Introduction}

Khalil Kariman

khalil.kariman@uwa.edu.au

1 UWA School of Agriculture and Environment, The University of Western Australia, Perth, WA 6009, Australia

2 SoilsWest, Centre for Sustainable Farming Systems, Food Futures Institute, Murdoch University, Murdoch, WA 6150, Australia

3 Department of Primary Industries and Regional Development, Northam, WA 6401, Australia

4 Institute of Ecology and Earth Sciences, University of Tartu, Ulikooli 18, 50090 Tartu, Estonia
The Australian native fungus Austroboletus occidentalis (Boletaceae, Basidiomycota) establishes feremycorrhizal (FM) symbiosis, conferring significant growth and nutritional benefits to diverse host plants, including the Australian native plant jarrah (Eucalyptus marginata) (Kariman et al. 2012, 2014), mycorrhizal crops such as wheat (Triticum aestivum) and barley (Hordeum vulgare), as well as the non-mycorrhizal crop canola (Brassica napus) (Kariman et al. 2020). It is known that all currently documented Austroboletus species (except $A$. occidentalis) form ectomycorrhizal (ECM) symbiosis with plants (Orlovich and Cairney 2004; Smith et al. 2013; Vasco Palacios 2016), suggesting that the FM symbiosis has evolved from the ECM symbiosis 
as manifested in an Austroboletus species native to Australia within the harsh, nutrient-poor jarrah forest ecosystem. In contrast to all known mycorrhizal/endophytic associations, in FM symbiosis, fungal hyphae do not colonize plant roots (Kariman et al. 2014, 2018, 2020). Hence, functional pathways in the FM symbiosis are different from those in conventional arbuscular mycorrhizal (AM) and (to some extent) ECM symbioses. A direct intraradical nutrient exchange between host plants and fungal partners occurs in AM/ECM symbioses, but not in the FM symbiosis due to lack of root colonization; however, both FM and ECM symbioses exhibit organic acid anion-mediated nutrient solubilization (Kariman et al. 2014, 2020). Therefore, the nutritional benefits of the FM symbiosis are attributed primarily to the fungal role in rhizosphere modification and nutrient solubilization/ mobilization (Kariman et al. 2014, 2020).

Nitrogen $(\mathrm{N})$ is an integral component of key biomolecules (e.g., chlorophyll, amino acids and nucleic acids), and its supply is crucial for plant growth and productivity in agroecosystems (Berman-Frank et al. 2003). To meet the increasing $\mathrm{N}$ demand in farming systems, synthetic $\mathrm{N}$ fertilizers are intensively used; in 2022, the global consumption worldwide is estimated to exceed 110 million tons of N (FAOSTAT 2019). Nitrogen fertilizers are costly and energy-intensive to produce, and may lead to severe or even irreversible damages to the environment, including nitrate $\left(\mathrm{NO}_{3}{ }^{-}\right)$pollution of surface- and groundwater, formation of coastal dead zones, and elevated nitrous oxide and carbon dioxide emissions (Eickhout et al. 2006). It is crucial to boost biological $\mathrm{N}_{2}$ fixation in farming systems to reduce the use of synthetic $\mathrm{N}$ fertilizers. Roughly, 40 million tons of fixed $\mathrm{N}$ per year are provided via biological $\mathrm{N}_{2}$ fixation in terrestrial ecosystems across the globe (Galloway et al. 1995), which needs to be enhanced to ensure environmental sustainability while maintaining the economic viability of farming systems. Symbiotic (e.g., Rhizobium and Frankia) and free-living (e.g., Azotobacter and Azospirillum) bacteria are among the main diazotrophs (Mus et al. 2016).

Root fungal symbionts such as AM and ECM fungi have been shown to synergistically interact with both free-living and symbiotic diazotrophs in soil, providing additional $\mathrm{N}$ benefits to host plants (Paul et al. 2007; Sabannavar and Lakshman 2008). Biological $\mathrm{N}_{2}$ fixation has been reported exclusively in the prokaryotes (Mus et al. 2016); we accordingly hypothesize that the improved $\mathrm{N}$ nutrition of Australian native plants (Kariman et al. 2014) and agricultural crops (Kariman et al. 2020) in symbiosis with the FM fungus $A$. occidentalis in sandy soils low in organic matter (Kariman et al. 2014, 2020) was due to the stimulation of the activity of rhizosphere microbial communities, including free-living diazotrophs.

Arbuscular mycorrhizal and ECM fungi are unable to use complex organic substances as a carbon (C) source (Smith and Read 2008; Shah et al. 2016; Zak et al. 2019), while the organic matter decomposition potential of the FM fungus $A$. occidentalis is currently unknown and needs to be explored. However, similar to ECM fungi, A. occidentalis has a degree of saprotrophic capacity, meaning it does not require a living host plant and can easily grow on synthetic growth media containing hexoses such as glucose (Kariman et al. 2014), which is an advantage in large-scale inoculum production. In contrast, AM fungi are obligate biotrophs, leading to high cost of inoculum production as an obstacle hindering (at least partially) their promising potential as agricultural bioinoculants.

The FM fungus establishes symbiosis with AM, ECM, and non-mycorrhizal plants (Kariman et al. 2014, 2020) and the inoculum of this fungus is inexpensive to mass-produce (Kariman et al. unpublished); hence, it is imperative to explore and possibly exploit the fungus-mediated nutritional benefits (e.g., N, P, Zn) in crop production systems. The present study was conducted to (i) explore the potential of the FM fungus $A$. occidentalis, alone or in combination with free-living diazotrophs consortium, to improve growth and $\mathrm{N}$ nutrition of wheat plants grown under $\mathrm{N}$ deficiency conditions, (ii) characterize soil chemical/microbial factors linked with symbiotic $\mathrm{N}$ nutritional benefits to host plants via assessing soil $\mathrm{N}$ forms $\left(\mathrm{NO}_{3}{ }^{-}-\mathrm{N}, \mathrm{NH}_{4}{ }^{+}-\mathrm{N}\right.$, and total $\left.\mathrm{N}\right)$ and changes in soil microbial composition, and (iii) determine the capacity of A. occidentalis to utilize different sugars and lignocellulosic substrates as a food source in vitro.

\section{Materials and methods}

\section{Soil physicochemical characteristics}

To conduct a controlled-environment trial, non-fertilized and naturally $\mathrm{N}$-depleted soil was collected (at $0-10 \mathrm{~cm}$ depth) from the Shenton Park Field Station (-31.948583, 115.793917), Shenton Park, Western Australia (WA). The soil was air-dried and sieved through a $2-\mathrm{mm}$ sieve to remove large debris and root fragments. The soil physicochemical properties were determined according to the methods described by Rayment and Lyons (2011): texture loamy sand (sand: $81.6 \%$; clay: $12.5 \%$; silt: $5.8 \%) ; \mathrm{pH}\left(\mathrm{CaCl}_{2}\right)$ 5.3; $\mathrm{NH}_{4}{ }^{+}-\mathrm{N} 3 \mathrm{mg} \mathrm{kg}^{-1} ; \mathrm{NO}_{3}{ }^{-}-\mathrm{N} 1 \mathrm{mg} \mathrm{kg}^{-1}$; Colwell P $5 \mathrm{mg} \mathrm{kg}^{-1}$; Colwell potassium (K) $17 \mathrm{mg} \mathrm{kg}^{-1}$; sulfur (S, potassium chloride extraction) $2.3 \mathrm{mg} \mathrm{kg}^{-1}$; and organic $\mathrm{C}$ $11.6 \mathrm{~g} \mathrm{~kg}^{-1}$.

\section{Fungal inoculum production}

The A. occidentalis AB15 was used for the present study, which was isolated and purified from a fresh fruiting body collected from Jarrahdale (WA, Australia) as previously 
described (Kariman et al. 2020). Vermiculite (grade 2, $2-4 \mathrm{~mm})$ was mixed with peat moss $(5: 1 \mathrm{v} / \mathrm{v})$ to produce a substrate for hyphal inoculum production. Two hundred milliliters of the vermiculite-peat moss substrate was placed into each 500-mL polycarbonate jar and autoclaved at $121{ }^{\circ} \mathrm{C}$ for $15 \mathrm{~min}$. Subsequently, all jars received $125 \mathrm{~mL}$ of a glucosebased liquid growth medium (Lambilliotte et al. 2004) and were autoclaved again $\left(121^{\circ} \mathrm{C}, 15 \mathrm{~min}\right)$. Jars were placed under a laminar flow (aseptic conditions) to cool down, and each jar was inoculated with 10 hyphal plugs $(5 \mathrm{~mm}$ in diameter) taken from the 6-week-old fungal colonies growing on potato dextrose agar (PDA) plates at $20^{\circ} \mathrm{C}$. The inoculated jars were then closed, and gently shaken to mix the hyphal plugs with the substrate, and the lids were left slightly loose to allow air exchange. The jars were incubated at $20^{\circ} \mathrm{C}$ for 10 weeks to produce the hyphal inoculum.

\section{Isolation of free-living diazotrophs from soil}

Two different soil samples were used to isolate the freeliving diazotrophs, including the soil used for our controlled-environment trial, and a soil sample collected from Jarrahdale, WA ( $-32.318397,116.042577)$. The Jarrahdale soil physicochemical properties were determined following the methods described by Rayment and Lyons (2011): texture sandy loam (sand: $57.5 \%$; clay: $20.8 \%$; silt: $21.6 \%$ ); $\mathrm{pH}\left(\mathrm{CaCl}_{2}\right)$ 5.5; $\mathrm{NO}_{3}^{-}-\mathrm{N} 4 \mathrm{mg} \mathrm{kg}^{-1}$; Colwell $\mathrm{P} 6 \mathrm{mg} \mathrm{kg}^{-1}$;

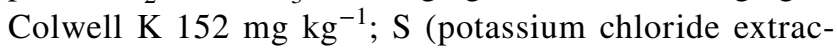
tion) $6.4 \mathrm{mg} \mathrm{kg}^{-1}$; and organic $\mathrm{C} 40 \mathrm{~g} \mathrm{~kg}^{-1}$. A Jarrahdale soil subsample $(10 \mathrm{~g})$ was added to $500-\mathrm{mL}$ Erlenmeyer flasks containing $100 \mathrm{~mL}$ of sterile deionized (DI) water and shaken at $150 \mathrm{rpm}$ for $30 \mathrm{~min}$. Then, serial dilutions of $10^{-3}$ to $10^{-5}$ were prepared in sterile DI water, and $0.1 \mathrm{~mL}$ aliquots of each serial dilution were inoculated onto plates containing $25 \mathrm{~mL}$ of Burk's N-free medium (sucrose: $20 \mathrm{~g}$ $\mathrm{L}^{-1} ; \mathrm{K}_{2} \mathrm{HPO}_{4}: 0.8 \mathrm{~g} \mathrm{~L}^{-1} ; \mathrm{KH}_{2} \mathrm{PO}_{4}: 0.2 \mathrm{~g} \mathrm{~L}^{-1} ; \mathrm{MgSO}_{4} \cdot 7 \mathrm{H}_{2} \mathrm{O}$ : $0.2 \mathrm{~g} \mathrm{~L}^{-1} ; \mathrm{CaCl}_{2} \cdot 2 \mathrm{H}_{2} \mathrm{O}: 90 \mathrm{mg} \mathrm{L}^{-1} ; \mathrm{FeCl}_{3}: 1.45 \mathrm{mg} \mathrm{L}^{-1}$; $\mathrm{Na}_{2} \mathrm{MoO}_{4} \cdot 2 \mathrm{H}_{2} \mathrm{O}: 0.25 \mathrm{mg} \mathrm{L}^{-1}$; agar: $15 \mathrm{~g} \mathrm{~L}^{-1}$; $\mathrm{pH}$ : 7.0). The inoculated plates were incubated at $25^{\circ} \mathrm{C}$ for $3-5$ days. The growing colonies were considered diazotrophs and were re-inoculated onto Burk's $\mathrm{N}$-free medium plates to confirm their diazotrophic activity. After 3-5 days of growth at $25{ }^{\circ} \mathrm{C}$, morphologically different isolates were selected, named, and maintained on nutrient agar (NA; $\mathrm{g} \mathrm{L}^{-1}$, yeast extract: 3, peptone: $5, \mathrm{NaCl}: 5$, agar: $15, \mathrm{pH}: 6.8$ ) plates for short-term storage at $4{ }^{\circ} \mathrm{C}$, or in nutrient broth $(\mathrm{NB}$; same composition as NA, but without agar) medium amended with $20 \%(\mathrm{v} / \mathrm{v})$ glycerol for long-term storage $\left(-80^{\circ} \mathrm{C}\right)$.

\section{Production of diazotrophs inoculum}

To produce the inoculum of a given isolate, a loop of bacterial colonies from NA plates was transferred to Erlenmeyer flasks containing $50 \mathrm{~mL}$ of autoclaved NB medium, and incubated on a shaker $(100 \mathrm{rpm})$ at $25{ }^{\circ} \mathrm{C}$ for $48 \mathrm{~h}$. The bacterial cells were subsequently pelleted by centrifugation (1968 $\mathrm{g}$ for $10 \mathrm{~min}$ ). The supernatant was discarded, and the bacterial cells were resuspended in $50 \mathrm{~mL}$ of $20 \mathrm{mM}$ $\mathrm{MgSO}_{4}$ by manually inverting the tubes five times. The number of colony-forming units (CFU) per milliliter was counted on NA plates and adjusted to $3 \times 10^{8} \mathrm{CFU} / \mathrm{mL}$ for inoculation. To prepare the diazotrophs consortium, $25 \mathrm{~mL}$ aliquots of each diazotroph inoculum were pooled together; hence, $1-\mathrm{mL}$ consortium contained $7.5 \times 10^{7} \mathrm{CFU}$ of each diazotroph isolate.

\section{Molecular identification of the diazotrophs}

Four diazotroph isolates were selected for the controlledenvironment trial, including SP5, SP12, and SP15 (from the Shenton Park soil) and J7 (from the Jarrahdale soil). For each isolate, DNA was extracted from pure bacterial cells growing on NA plates following a method described by Cenis (1992). The V4 region of the 16S rRNA gene was amplified using the 515F/806R primer pair (Liu et al. 2007), and amplicons were sequenced on an Illumina MiSeq platform (see below for the sequencing details and bioinformatics analysis).

\section{Controlled-environment trial}

The controlled-environment trial was carried out in a completely randomized design with four replications. Four inoculation treatments included control (no added microbes: only containing soil indigenous microbes), diazotrophs (a consortium of four free-living diazotroph isolates in $20 \mathrm{mM}$ $\mathrm{MgSO}_{4}$ ), $\mathrm{FM}$ (hyphal inoculum of $\mathrm{A}$. occidentalis), and dual (co-inoculation with A. occidentalis and diazotrophs consortium). To equalize the amount of nutrients/organic matter across treatments, heat-sterilized fungal inoculum (for control and diazotrophs treatments; added before sowing) or heat-sterilized diazotrophs inoculum (for control and FM treatments; added during sowing) was also added to the soil in respective treatments.

To prepare the inoculation treatments, the living or sterilized hyphal inoculums were thoroughly mixed with soil ( $1: 10 \mathrm{v} / \mathrm{v}$, equivalent to $70 \mathrm{~mL}$ of inoculum per $\mathrm{kg}$ soil) within clean plastic bags, and $2 \mathrm{~kg}$ of the prepared mixtures was placed into pots. Prior to sowing, an aqueous $\mathrm{KNO}_{3}$ solution was added to the soil $\left(33 \mathrm{mg} \mathrm{N} \mathrm{kg}^{-1}\right)$ to assist with the early establishment of plants; there was no additional $\mathrm{N}$ input during the growth period in order to have $\mathrm{N}$ deficiency conditions. Pots also received optimal rates of all other nutrients (except $\mathrm{P}$, to ensure a more effective symbiosis) via the addition of the following basal nutrient salts (in $\mathrm{m} \mathrm{kg}^{-1}$ ) to the soil as solutions: $\mathrm{K}_{2} \mathrm{SO}_{4}: 125 ; \mathrm{MgSO}_{4} \cdot 7 \mathrm{H}_{2} \mathrm{O}: 81.2$; 
$\mathrm{CaCl}_{2} \cdot 2 \mathrm{H}_{2} \mathrm{O}: 146.7 ; \mathrm{MnSO}_{4} \cdot \mathrm{H}_{2} \mathrm{O}: 9.2 ; \mathrm{CuSO}_{4} \cdot 5 \mathrm{H}_{2} \mathrm{O}: 2.1$; $\mathrm{ZnSO}_{4} \cdot 7 \mathrm{H}_{2} \mathrm{O}: 8.8 ; \mathrm{Na}_{2} \mathrm{MoO}_{4} \cdot 2 \mathrm{H}_{2} \mathrm{O}: 0.2$; and $\mathrm{H}_{3} \mathrm{BO}_{3}: 0.7$.

Wheat seeds (cv. Mace; developed by the USDA-ARS and the Nebraska Agricultural Experiment Station) were surface-sterilized as described previously (Kariman et al. 2020), and submerged in DI water for $3 \mathrm{~h}$ to imbibe. The imbibed seeds were drained and incubated in the dark at $4{ }^{\circ} \mathrm{C}$ overnight to break any possible dormancy and achieve uniform germination. Ten seeds were sown per pot (at $2 \mathrm{~cm}$ depth), and each seed received $1 \mathrm{~mL}$ of the diazotrophs consortium (in diazotrophs and dual treatments) or autoclaved diazotrophs consortium (in control and FM treatments). All pots were covered with sterile plastic beads $(3-4 \mathrm{~mm}$ in diameter, $35 \mathrm{~g}$ per pot) to minimize cross contamination and reduce evaporation. Seedlings were thinned to six seedlings/pot 1 week after sowing. To assure an effective diazotroph inoculation, seedlings were re-inoculated with $1 \mathrm{~mL}$ of the living or sterilized diazotrophs consortium (added to the soil around each seedling) 2 weeks after planting. Plants were grown in controlled-environment growth chambers at $12 / 12 \mathrm{~h}$ light/dark and $20 / 15^{\circ} \mathrm{C}$ day/night temperature. During the growth period, pots were watered to field capacity (14\% volumetric water content).

\section{Plant growth and nutritional analyses}

Plants were harvested after 7 weeks of growth. Shoots were cut $1 \mathrm{~cm}$ above the soil surface, and were dried in an oven $\left(70{ }^{\circ} \mathrm{C}\right.$ for $\left.72 \mathrm{~h}\right)$. Roots were separated from the bulk soil and washed over a 2-mm sieve to remove debris and the adhering soil particles. The root total fresh weight was measured for all samples, and each root system was subsequently split into two subsamples, one of which was weighed and oven-dried $\left(70{ }^{\circ} \mathrm{C}\right.$ for $72 \mathrm{~h}$ ) to be used for dry weight calculations, and the other subsample was stored in 50\% ethanol (v/v) for root AM colonization measurements.

Soil from each pot was homogenized manually, and two subsamples (about $50 \mathrm{~g}$ each) were subsequently placed in zip-lock bags, one of which was immediately placed in foam-insulated container containing dry ice $\left(-78^{\circ} \mathrm{C}\right)$ and stored at $-20^{\circ} \mathrm{C}$ to be used for microbial analysis. The other soil sample was air-dried and used for mineral and total $\mathrm{N}$ analyses.

Oven-dried shoot samples were ground to a fine powder, and a measured amount (195-205 mg, the exact weight recorded for nutrient content calculations) was digested in a mixture of nitric and perchloric acid $(4: 1 \mathrm{v} / \mathrm{v})$. The sample digests were used to determine the concentration of $\mathrm{P}$, $\mathrm{K}, \mathrm{Ca}, \mathrm{Mg}, \mathrm{S}, \mathrm{Zn}, \mathrm{Fe}$, and $\mathrm{Mn}$ using inductively coupled plasma optical emission spectrometry (ICP-OES; Optima 5300 DV; PerkinElmer). Shoot N content was determined using a combustion analyzer (Elementar Vario Macro, Hanau, Germany).

\section{Determination of soil $\mathrm{N}$ forms}

For soil extractable $\mathrm{NH}_{4}{ }^{+}$and $\mathrm{NO}_{3}{ }^{-}$content determination, soil samples were extracted using $0.5 \mathrm{M} \mathrm{K}_{2} \mathrm{SO}_{4}$ and the mineral $\mathrm{N}$ fractions were quantified spectrophotometrically (Joergensen and Brookes 1990; Rayment and Lyons 2011). To determine soil total $\mathrm{N}$, the air-dried soil samples were ground to a fine powder, and total $\mathrm{N}$ was measured using the combustion analyzer.

\section{Root colonization by indigenous AM fungi}

Root subsamples were cleared in $10 \% \mathrm{w} / \mathrm{v} \mathrm{KOH}$ and stained as previously described (Kariman et al. 2012), and the percentage of root AM colonization was determined following the gridline intersect method (Giovannetti and Mosse 1980) by counting at least 250 intersects per sample.

\section{Soil DNA extraction, amplicon sequencing, and bioinformatics analysis}

Soil subsamples $(0.3 \mathrm{~g})$ were used to extract DNA from four biological replicates per treatment $(n=16)$ using a Qiagen PowerSoil Kit; the manufacturer's protocol was followed throughout the process with the sole modification of reloading the final elution buffer onto a filter column in order to maximize the DNA recovery yield. The V4 region of the bacterial 16S rRNA gene was targeted for amplicon sequencing using the 505F/806R primer pair (Liu et al. 2007), which was carried out at the Australian Genome Research Facility (Melbourne, Australia) using an Illumina MiSeq v2 platform (250 PE chemistry).

Sequence analysis was performed using the QIIME2 pipeline (Bolyen et al. 2019). In total, 2.88 million reads were generated for the V4 region, out of which about 580,000 reads $(\sim 20 \%)$ were retained after quality filtering steps such as read overlap detection, de-noising, and chimera filtering. Amplicon single variants (ASVs) were selected using the DADA2 plugin after trimming the first and last five nucleotides of each sequence. Taxonomic assignment was carried out using the Scikit-learn algorithm within the QIIME2 pipeline. Chloroplast- and mitochondria-like sequences as well as low-abundance ASVs were discarded ( $<20$ hits, representing $15 \%$ of the dataset). Due to the unbalanced read count among samples, a rarefaction step (set at 19,276) was performed prior to the statistical analyses. The Bray-Curtis dissimilarity matrix was employed to generate the non-metric multidimensional scaling (NMDS) plot based on the relative microbial abundance using the "metaMDS" function of the "vegan" package in $R$ (Oksanen et al. 2019). Similarity percentage analysis (SIMPER, implemented in the "vegan" $\mathrm{R}$ package) was also performed to quantify dissimilarity between groups and better explain the observed clustering 
(Clarke 1993). Shannon diversity was calculated using the function "Diversity" in the "vegan" package and visualized using the ggplot2 package (Wickham et al. 2020).

Due to the short length of the targeted amplicons, fine taxonomic resolution is rarely achieved for soil microorganisms. Here, two diazotrophs (SP5 and SP12) were taxonomically identified as the same Arthrobacter species, despite presenting different morphology (Fig. S1). A phylogenetic approach was taken to differentiate these two isolates. The 16S rRNA V4 region sequences obtained from the pure cultures of these two diazotroph isolates were analyzed separately following the same methodology as described above. A total of 331,000 quality reads were binned into $10 \mathrm{ASVs}$, all of which were identified as an unknown Arthrobacter species. The ASV sequences were extracted and placed into a comprehensive phylogenetic reference tree (Hug et al. 2016). Reference sequences were aligned using the INFERNAL, and tree construction was performed using the RAxML algorithm according to the GTRGAMMA substitution model. The ASV sequences of SP5 and SP12 isolates were concatenated with the reference sequences and aligned as described above. Reference package and the alignment were then fed into the "pplacer" (Matsen et al. 2010) with the flag "-keep-at-most" set to 1. Phylogenetic placements were then visualized and annotated in IToL v5 (Letunic and Bork 2019). All 16S rRNA gene sequences were deposited in the European Nucleotide Archive (accession number: PRJEB46901).

\section{C source utilization test}

An in vitro experiment was conducted to explore the fungal capacity to utilize different $C$ sources. There were nine treatments: PDA (as a universal/standard fungal growth medium), vermiculite-peat moss mixture (VPM) $(3: 1 \mathrm{v} / \mathrm{v})$, $\mathrm{VPM}+$ glucose, $\mathrm{VPM}+$ fructose, $\mathrm{VPM}+$ sucrose, and five lignocellulosic substrates including organic compost (made of tree-trimming green waste, Richgro Pty Ltd, WA), pine sawdust shavings (Pinus radiata, softwood), Tasmanian blue gum sawdust (Eucalyptus globulus, hardwood), wheat (Triticum aestivum) straw, and lupin hay (narrow-leafed lupin, Lupinus angustifolius). Wheat straw and lupin hay substrates were pulverized into small pieces $(<10 \mathrm{~mm})$ prior to the in vitro trial. The PDA plates were prepared $(39 \mathrm{~g}$ medium $\mathrm{L}^{-1}$ ). To study the fungal capacity to utilize simple sugars, $200 \mathrm{~mL}$ of the VPM medium was supplemented with $125 \mathrm{~mL}$ of DI water (the VPM treatment; no added sugar), or $125 \mathrm{~mL}$ of $85 \mathrm{mM}$ glucose or fructose, and autoclaved $\left(121^{\circ} \mathrm{C}, 15 \mathrm{~min}\right)$. To avoid possible sucrose hydrolysis during the autoclaving, the sucrose solution $(85 \mathrm{mM})$ was filtersterilized $(0.2 \mu \mathrm{m}$, Filtropur, Sarstedt, Germany) and added to the VPM medium after autoclaving $(125 \mathrm{~mL}$ of solution for $200 \mathrm{~mL}$ of medium). The lignocellulosic substrates were soaked in DI water for $12 \mathrm{~h}$, drained for $1 \mathrm{~h}$, and autoclaved $\left(121^{\circ} \mathrm{C}, 15 \mathrm{~min}\right)$.

For all treatments, $25 \mathrm{~mL}$ substrate was placed in each sterile Petri plate, and there were five replicates per treatment. All plates were inoculated with a triangle hyphal plug $(7 \times 7 \times 7 \mathrm{~mm})$ that was taken from the actively growing (4-week-old) colonies of $A$. occidentalis on PDA plates. The hyphal plugs were placed on the media upside down, i.e., the mycelia were in direct contact with the medium. Inoculated plates were incubated at $20^{\circ} \mathrm{C}$ in the dark for 4 weeks. Substrates were examined visually and also under a dissecting microscope. The mycelial colonization of the medium was considered a capacity to utilize the respective $\mathrm{C}$ source, and the colony diameter was measured.

\section{Statistical analysis}

The controlled-environment plant experiment was conducted in a completely randomized design with four replicates. The in vitro $C$ source utilization test was carried out with five replicates. The homogeneity of variances, normality of the residuals, and independence of samples were considered during the data analysis. To detect significant differences among treatments, analysis of variance (ANOVA) was performed followed by the Fisher's protected least significant difference (LSD) test at a probability level of $95 \%(p \leq 0.05)$. PERMANOVA was performed using the function "adonis" within the "vegan" package (in $R$ ) to detect significant differences among microbial clusters in the NMDS plot.

\section{Results}

\section{Plant growth and nutritional responses to $A$. occidentalis and/or diazotrophs inoculums}

All inoculated plants had significantly higher shoot (Fig. 1a) and root (Fig. 1b) biomass compared to the uninoculated (control) plants. Significantly greater shoot biomass was observed in plants inoculated with diazotrophs (by 25\%), A. occidentalis (by 101\%), and combined inoculums (by 106\%) compared to the control (Fig. 1a-b). Both FM and dual treatments had a greater shoot and root biomass than the diazotrophs treatment, but there was no significant difference between the FM and dual treatments.

All wheat plants showed $\mathrm{N}$ deficiency symptoms (chlorosis), and the shoot $\mathrm{N}$ concentration was below $29 \mathrm{~g} / \mathrm{kg}$ dry weight in all treatments, indicating $\mathrm{N}$ deficiency in wheat at the tillering stage (Reuter and Robinson 1997). All inoculated plants had enhanced shoot nutrient content (including $\mathrm{N}, \mathrm{P}, \mathrm{K}, \mathrm{Mg}, \mathrm{Zn}, \mathrm{Cu}$, and $\mathrm{Mn}$ ) compared with the control, and the contents of these nutrients (except $\mathrm{Cu}$ in FM treatment) were significantly higher in plants inoculated with 
Fig. 1 Shoot (a) and root (b) dry biomass of wheat (Triticum aestivum) plants grown under $\mathrm{N}$ deficiency for 7 weeks. Treatments are control, no added microbes, only containing soil indigenous microbes; diazotrophs, inoculated with a consortium containing four free-living diazotroph isolates; FM, inoculated with the hyphal inoculum of Austroboletus occidentalis; and dual, inoculated with both diazotrophs and $A$. occidentalis inoculums. Bars with different letters are significantly different according to the Fisher's protected least significant difference test $(p \leq 0.05)$. Error bars indicate standard errors $(n=4)$ a)

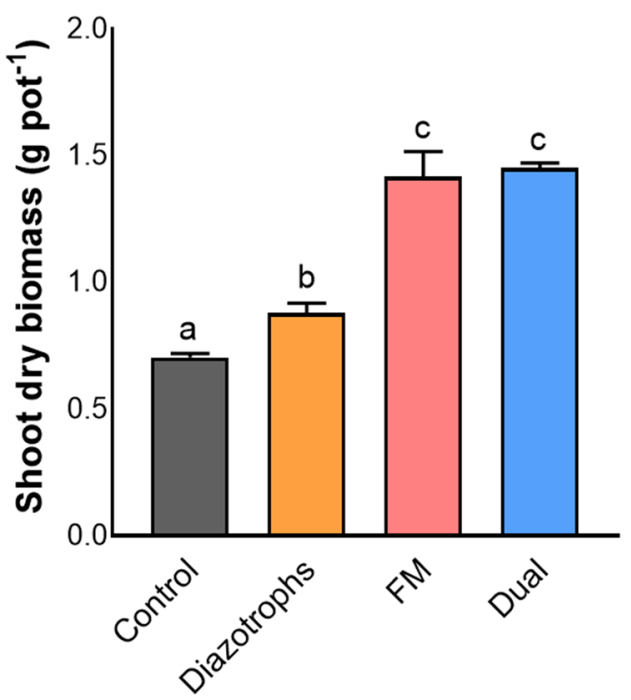

b)

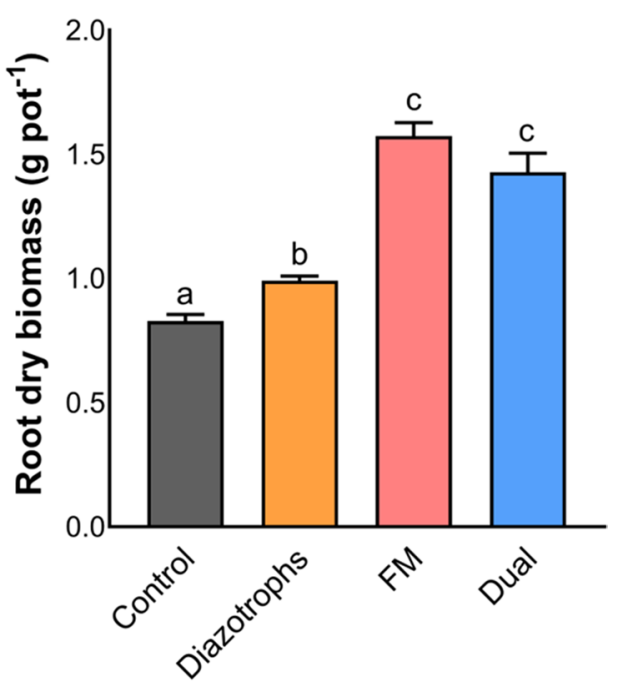

the FM fungus (in both FM and dual treatments) compared to those inoculated only with diazotrophs (Table 1). Shoot $\mathrm{N}$ content was significantly higher in plants inoculated with diazotrophs (by 15\%), FM fungus (by 45\%), and dual inoculums (by 67\%) compared to the control treatment. Dually inoculated plants had the highest shoot nutrient contents $(\mathrm{N}$, $\mathrm{P}, \mathrm{K}, \mathrm{S}, \mathrm{Mg}, \mathrm{Zn}, \mathrm{Cu}$, and $\mathrm{Mn}$ ) across treatments, indicating synergistic interactions between $A$. occidentalis and the added diazotrophs. Shoot Fe content did not differ significantly between control and diazotrophs treatments, whereas the presence of $A$. occidentalis (in both FM and dual treatments) significantly enhanced the shoot Fe content in comparison with the control. Furthermore, both diazotrophs and dual treatments had greater shoot $\mathrm{S}$ content than control, but the shoot $\mathrm{S}$ content of plants inoculated with $A$. occidentalis was not significantly different from the control.

\section{Soil mineral $\mathbf{N}$ and total $\mathbf{N}$ contents}

The soil extractable $\mathrm{NH}_{4}{ }^{+}-\mathrm{N}$ content did not differ significantly between the control and treatments inoculated with either diazotrophs or the FM fungus, whereas it was higher in the FM treatment compared to the diazotrophs (Fig. 2a). The dual treatment had significantly higher soil extractable $\mathrm{NH}_{4}{ }^{+}-\mathrm{N}$ content compared to both the control and diazotrophs treatments. Soil $\mathrm{NO}_{3}{ }^{-}-\mathrm{N}$ content was significantly lower in all the inoculated treatments compared to the control (Fig. 2b). The lowest soil $\mathrm{NO}_{3}{ }^{-}-\mathrm{N}$ content was in the FM and dual treatments, which had the highest root biomass among treatments (Fig. 1b). Soil total $\mathrm{N}$ in the diazotrophs and FM treatments was not significantly different from the control, but the diazotrophs treatment had higher soil total $\mathrm{N}$ than the FM treatment (Fig. 2c). The dual treatment had higher (by 13-24\%) soil total N compared to other treatments.

\section{Soil microbiome analysis based on the $16 \mathrm{~S}$ rRNA gene sequencing}

The microbiome analysis revealed the presence of indigenous bacteria with $\mathrm{N}_{2}$-fixing potential in soils from all treatments at the end of the growth period, which included Arthrobacter sp., Paraburkholderia bryophila, Paraburkholderia tuberum, Bacillus flexus, and Mesorhizobium sp. (bold and highlighted in dark green, Table S2). The $16 \mathrm{~S}$ rRNA amplicon sequencing also revealed that the presence of the FM fungus led to a slight but significant shift of the soil microbiome in both FM and dual treatments, which was revealed by the NMDS ordination plot and PERMANOVA analysis (Fig. 3a). In FM and dual treatments, the microbial community compositions were clustered away from the control and diazotrophs treatments that had overlapping clusters, suggesting that the FM fungus was the primary driver of the changes in the soil microbiome. No change in the ASVs richness was observed across treatments (Fig. 3b), suggesting that the FM-mediated microbiome shift was limited to certain bacterial taxa. The SIMPER analysis (Table S1) indicated comparable dissimilarities between groups (control/dual $=0.269$; control $/ \mathrm{FM}=0.302$; control/ diazotrophs $=0.284$; diazotrophs/dual $=0.276$; diazotrophs $/$ $\mathrm{FM}=0.267$; and $\mathrm{FM} /$ dual $=0.265$ ), with the top $20 \mathrm{ASVs}$ explaining only $\sim 10 \%$ of the observed dissimilarities.

The relative abundance of the four added diazotroph isolates in soil was quantified for all treatments (Fig. 3c). The SP5 and SP12 isolates were taxonomically identified as the same unclassified Arthrobacter species, despite showing 


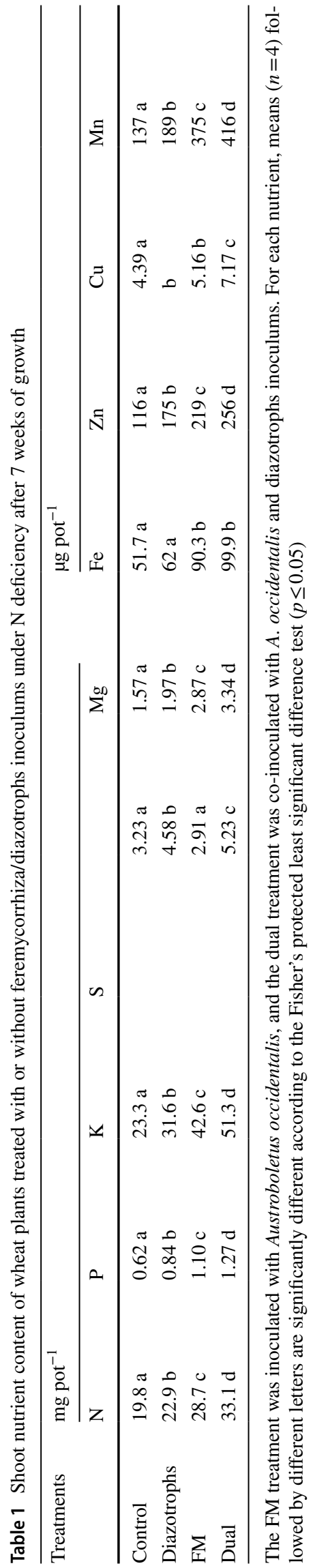

distinct morphology (Fig. S1). A phylogenetic approach was employed to achieve a better resolution of possible differences between these two isolates, which also identified both isolates as the same species closely related to Arthrobacter phenanthrenivorans Sphe3 (Fig. S2). The relative abundance of SP5/SP12 isolates was significantly higher in the diazotrophs and dual treatments compared to the control and FM treatments (Fig. 3c). Although SP5/SP12 isolates were present in the soil indigenous microbiome, their combined relative abundance was very low and did not differ significantly between the control and FM treatments. In addition, the SIMPER analysis (Table S1) also identified an unclassified Arthrobacter taxon that was enriched in the dual treatment, partially explaining the difference between the control and dual treatments. Based on their 16S rRNA gene sequences, SP15 and J7 isolates were clearly identified as Bacillus flexus and Paraburkholderia bryophila, with confidence scores of 0.98 and 0.96 , respectively. The relative abundances of SP15 and $\mathbf{J} 7$ isolates were not significantly different among the treatments.

\section{Root colonization by indigenous AM fungi}

The soil used for the current study contained an indigenous population of AM fungi. The addition of the microbial inoculums (diazotrophs and the FM fungus, alone or in combination) led to a significant reduction in AM colonization of wheat roots under $\mathrm{N}$ deficiency conditions (Fig. 4). Moreover, the root AM colonization was significantly lower in plants inoculated with the FM fungus and dually inoculated plants compared to non-inoculated plants and those inoculated with the diazotrophs.

\section{Fungal capacity to utilize different $C$ sources}

The in vitro $\mathrm{C}$ source utilization test revealed the limited extent of the saprotrophic capacity of A. occidentalis (Table 2). Substrate colonization by the fungus was considered an indication of $\mathrm{C}$ utilization capacity. The highest fungal colony diameter was observed on the standard PDA medium, which contained starch (a glucose polymer) and dextrose (D-glucose). The fungus did not colonize the unamended VPM medium, or the VPM medium supplemented with sucrose, but it colonized the VPM media supplemented with hexoses (glucose or fructose). The FM fungus was not able to colonize the media primarily containing lignocellulosic substrates such as organic compost, pine sawdust, blue gum sawdust, and lupin hay. However, the fungus colonized the wheat straw substrate, which contains considerable amounts of glucose (along with cellulose, hemicellulose, and lignin as the main components) (Collins et al. 2014). 

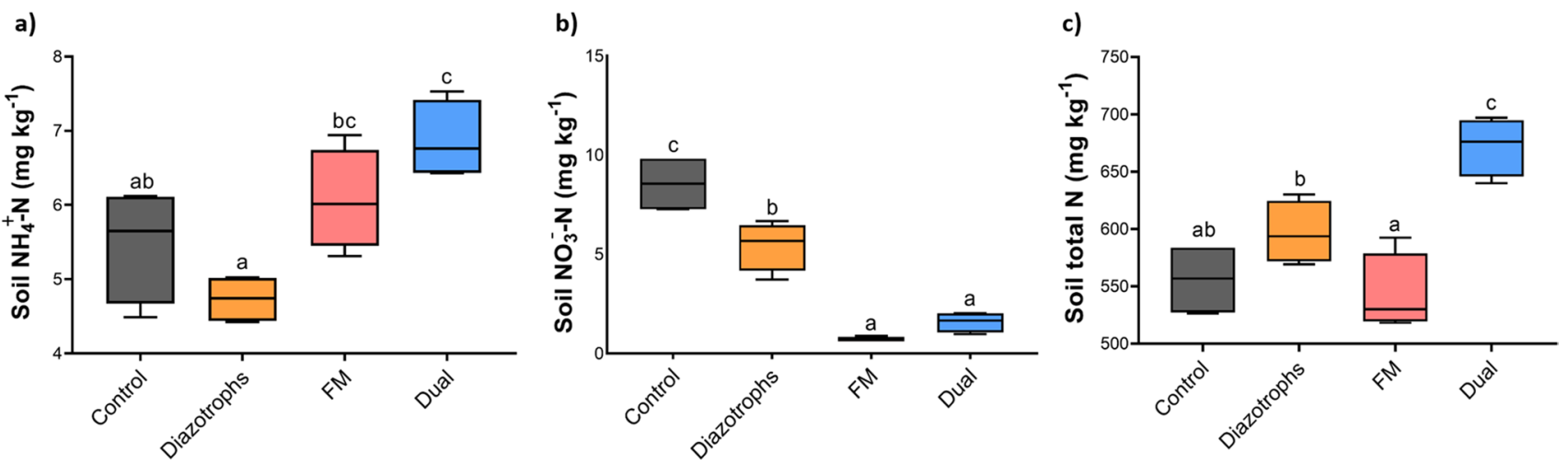

Fig. 2 Soil content of extractable $\mathrm{NH}_{4}{ }^{-} \mathrm{N}$ (a) and $\mathrm{NO}_{3}{ }^{-}-\mathrm{N}$ (b) and total $\mathrm{N}$ (c) at the end of the controlled-environment study (7 weeks). Control, no added microbes, only containing soil indigenous microbes; diazotrophs, inoculated with a consortium containing four free-living diazotroph isolates; FM, inoculated with the hyphal inocu-

lum of Austroboletus occidentalis; and dual, inoculated with both diazotrophs and A. occidentalis inoculums. For each parameter, bars with different letters are significantly different according to the Fisher's protected least significant difference test $(p \leq 0.05)$. Error bars indicate standard errors $(n=4)$

a

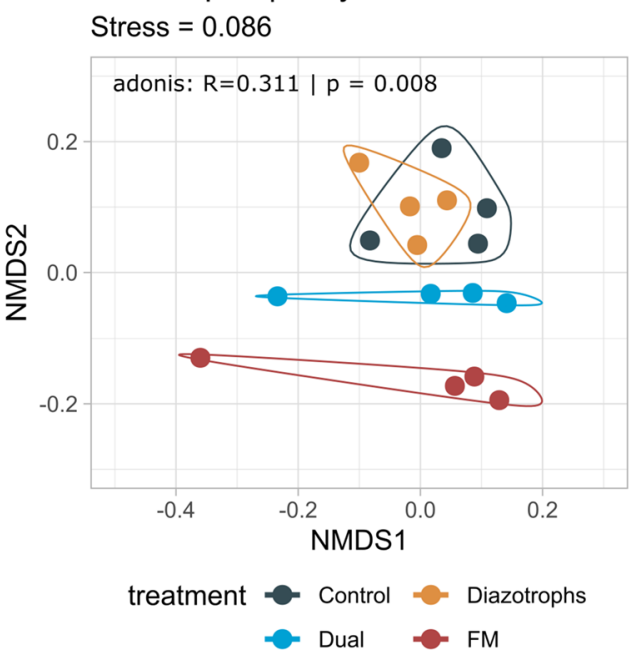

Fig. 3 Soil microbiome analysis based on the bacterial 16S rRNA gene sequences at the end of the controlled-environment study (7 weeks). a Non-metric multidimensional scaling (NMDS) analysis using the Bray-Curtis dissimilarity matrix. b Species richness in different treatments based on the amplicon single variants (ASVs). c Relative abundance of the four added diazotroph isolates in soil. Control, no added microbes, only containing soil indigenous microbes;

\section{Discussion}

The results demonstrated the positive effects of the FM fungus $A$. occidentalis on wheat growth and nutrition under $\mathrm{N}$ deficiency, which is a line with our previous observations on wheat, barley, and the non-mycorrhizal crop canola grown under nutrient deficiency conditions (Kariman et al. 2020). There was a synergistic interaction between A. occidentalis and soil free-living diazotrophs, diazotrophs, inoculated with a consortium containing four free-living diazotroph isolates; FM, inoculated with the hyphal inoculum of Austroboletus occidentalis; and dual, inoculated with both diazotrophs and $A$. occidentalis inoculums. Bars with different letters are significantly different according to the Fisher's protected least significant difference test $(p \leq 0.05)$. ns, not significant. Error bars indicate standard errors $(n=4)$

as reflected in higher shoot $\mathrm{N}$ content and shoot/root biomass of plants in the FM and dual treatments compared to the control and the diazotrophs treatments. Consistent with these results, the dually inoculated plants had significantly higher extractable $\mathrm{NH}_{4}{ }^{+}-\mathrm{N}$ compared to the control and diazotrophs treatments (Fig. 2), as well as the highest shoot $\mathrm{N}$ content (Table 1) and soil total $\mathrm{N}$ across the treatments (Fig. 2). Although plants in the dual treatment had higher shoot nutrient content than the fungus-only (FM) treatment, their shoot biomass was numerically higher 


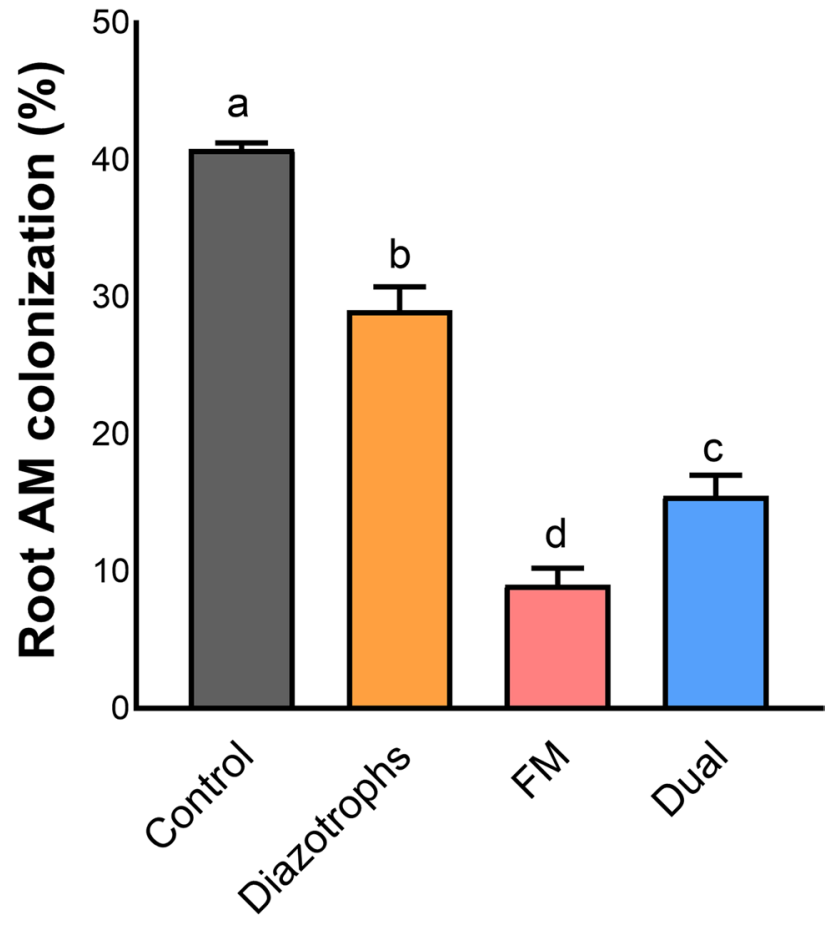

Fig. 4 Root colonization of 7-week-old wheat (Triticum aestivum) plants by soil indigenous arbuscular mycorrhizal (AM) fungi. Control, no added microbes, only containing soil indigenous microbes; diazotrophs, inoculated with a consortium containing four free-living diazotroph isolates; FM, inoculated with the hyphal inoculum of Austroboletus occidentalis; and dual, inoculated with both diazotrophs and A. occidentalis inoculums. Bars with different letters are significantly different according to the Fisher's protected least significant difference test $(p \leq 0.05)$. Error bars indicate standard errors $(n=4)$

Table 2 Capacity of the feremycorrhizal fungus Austroboletus occidentalis to colonize different organic substrates

\begin{tabular}{lll}
\hline Medium & Colonization & Colony diameter $(\mathrm{mm})^{*}$ \\
\hline PDA & + & $39.6 \pm 1.1 \mathrm{a}$ \\
VPM & - & NA \\
VPM + glucose & + & $20 \pm 1.3 \mathrm{~b}$ \\
VPM + fructose & + & $18.8 \pm 1.1 \mathrm{~b}$ \\
VPM + sucrose & - & NA \\
Organic compost & - & NA \\
Pine sawdust & - & NA \\
Blue gum sawdust & - & NA \\
Wheat straw & + & $11.4 \pm 0.4 \mathrm{c}$ \\
Lupin hay & - & $\mathrm{NA}$ \\
\hline
\end{tabular}

"Means \pm SE $(n=5)$. “+” indicates the fungal capacity to colonize the respective medium after 4 weeks of incubation at $20{ }^{\circ} \mathrm{C}$. "-." indicates lack of substrate colonization by the fungus. $P D A$ potato dextrose agar; $V P M$ vermiculite-peat moss mixture $(3: 1, \mathrm{v} / \mathrm{v})$. Means followed by different letters are significantly different according to the Fisher's protected least significant difference test $(p \leq 0.05)$. NA not any than the FM treatment, a possible indication of higher $\mathrm{C}$ allocation to the fungus and diazotrophs in the dual treatment. Soils in all inoculated treatments had significantly lower $\mathrm{NO}_{3}{ }^{-} \mathrm{N}$ content compared to the control, likely due to the greater root biomass of inoculated plants, which used the soil available $\mathrm{NO}_{3}{ }^{-}-\mathrm{N}$. This phenomenon was more pronounced in the FM and dual treatments, which had the lowest $\mathrm{NO}_{3}{ }^{-}-\mathrm{N}$ content across treatments, because of their larger root and shoot biomass (Fig. 1).

The improved $\mathrm{N}$ nutrition of plants in the FM (fungusonly) treatment compared to both control and diazotrophs treatments can be associated with the enhanced $\mathrm{N}_{2}$-fixing activities of the indigenous diazotroph populations that were detected in the field soil (bold and highlighted in green, Table S2). We assume that A. occidentalis enhanced the activity of indigenous soil-borne $\mathrm{N}_{2}$-fixing microbes, which might thereby account for the significant $\mathrm{N}$ nutritional benefits in the FM treatment. This was supported by the significant fungus-driven modification of the soil microbial community uncovered by NMDS ordination of the bacterial 16S rRNA gene amplicon data (Fig. 3a). The SIMPER analysis (Table S1) did not identify microorganisms that could explain a major part of the observed dissimilarity, suggesting that small (but critical) changes in the microbiome composition (Fig. 3a) could be linked to enhanced growth and nutritional benefits in inoculated plants. Indeed, with the addition of the diazotrophs consortium to the soil, the FM fungus further boosted the shoot content of $\mathrm{N}$ and other nutrients (Table 1), along with soil total N (Fig. 2c), which can be primarily attributed to the synergism between A. occidentalis and the added diazotrophs.

The dual treatment had the highest soil total $\mathrm{N}$ content, which can be attributed mainly to the organic $\mathrm{N}$ pool accumulated in biomass of the introduced fungus/ diazotrophs, because the soil total extractable mineral $\mathrm{N}$ $\left(\mathrm{NH}_{4}{ }^{+}-\mathrm{N}+\mathrm{NO}_{3}{ }^{-}-\mathrm{N}\right)$ content of the dual treatment only made a small proportion $(\sim 1.2 \%)$ of the total $\mathrm{N}$ (Fig. 2$)$. In addition to $\mathrm{N}$, shoot content of other nutrients (e.g., P, K, Zn) was also enhanced by $A$. occidentalis in both FM and dual treatments, which can be attributed to the fungal role in nutrient mobilization/solubilization (Kariman et al. 2014, 2020). Ectomycorrhizal fungi (i.e., the fungi that are functionally and taxonomically related to $A$. occidentalis) can mobilize nutrients from insoluble mineral sources (such as apatite, biotite, and muscovite) via excretion of organic acid anions (carboxylates) and protons, resulting in acidolysis of soil minerals by dismantling their crystalline structure (Courty et al. 2010). Our recent in vitro studies (Kariman et al. 2020) demonstrated the solubilization of the water-insoluble $\mathrm{P}$ forms, including calcium phosphate $(\mathrm{CaP}$, as hydroxyapatite), iron phosphate $\left(\mathrm{FePO}_{4}\right)$, and aluminum phosphate $\left(\mathrm{AlPO}_{4}\right)$ by $A$. occidentalis via exudation of organic acid anions (mainly oxalate, along with citrate and fumarate) into the 
solid agar-based media. The ${ }^{31} \mathrm{P}$ nuclear magnetic resonance (NMR) spectroscopy revealed the presence of similar P species in the media (dominated by orthophosphate and longchain inorganic polyphosphates), indicating that all three water-insoluble $\mathrm{P}$ compounds $\left(\mathrm{CaP}, \mathrm{FePO}_{4}\right.$, or $\left.\mathrm{AlPO}_{4}\right)$ were solubilized and transformed by the FM fungus. Moreover, $A$. occidentalis converted a large proportion of the solubilized $\mathrm{P}$ (free orthophosphate) into long-chain inorganic polyphosphates (up to $51 \%$ of total P in the media) (Kariman et al. 2020). Furthermore, a proportion of the nutritional improvement in the dual treatment can also be attributed to possible plant growth-promoting activities of the added diazotrophs (e.g., P solubilization, production of siderophores and phytohormones such as auxin) (Backer et al. 2018), which might have been stimulated by the FM fungus, leading to greater shoot biomass (Fig. 1a) and nutrient content (Table 1) in the dual treatment compared to the diazotrophs treatment. These are important findings within the agricultural context, as this novel symbiotic fungus as well as effective diazotrophs can be propagated on synthetic media containing hexoses (e.g., glucose), and be applied to enhance biological $\mathrm{N}_{2}$ fixation to benefit both AM and non-mycorrhizal crops (an important example of the latter is canola, whose growth and nutrition were enhanced by the FM fungus) (Kariman et al. 2020).

The biological processes governing the synergistic interactions between A. occidentalis and free-living diazotrophs remain to be elucidated. Synergism between mycorrhizal fungi and diazotrophs has been attributed to diverse factors, including the role of fungal partners in increasing the mobilization/solubilization of soil nutrients, particularly those involved in the biosynthesis of nitrogenase and the oxygen-carrying compound leghemoglobin (e.g., Fe, P, $\mathrm{Mo}$ ) and/or direct provision of $\mathrm{C}$ source for diazotrophs as organic acid anions (Olsson and Wallander 1998; Abd-Alla et al. 2014; Püschel et al. 2017). Based on the proximity of the bacterial symbionts and plant roots, the diazotrophs are classified into three main groups, namely free-living (e.g., Azotobacter and Azospirillum), endophytic (e.g., Azoarcus and Herbaspirillum), or endosymbiotic (e.g., Rhizobium and Frankia) (Mus et al. 2016). Endophytic and endosymbiotic diazotrophs rely directly on the $\mathrm{C}$ source provided by their associated host plants inside their roots, whereas the freeliving (rhizosphere-associative) diazotrophs typically gain their energy by oxidizing organic molecules released by roots, other organisms, or from decomposition of organic matter (Mus et al. 2016; Dellagi et al. 2020). Austroboletus occidentalis was previously shown to solubilize waterinsoluble $\mathrm{P}$ compounds via exudation of organic acid anions such as oxalate and citrate (Kariman et al. 2020), which may also act as a food source for free-living diazotrophs in soil, thus representing one of the possible mechanisms underlying the synergism we observed in our present study between $A$. occidentalis and free-living diazotrophs.
Nitrogen fixation by soil microbes is a gradual process that provides plants with a steady N supply (James 2000); microbe-mediated $\mathrm{N}_{2}$ fixation is accompanied by other nutritional (e.g., $\mathrm{P}, \mathrm{K}, \mathrm{Mg}, \mathrm{Fe}, \mathrm{Zn}$ ) benefits as we observed in the present study and previous studies (Abd-Alla et al. 2014; Püschel et al. 2017). This may result in nutritional biofortification of food/feed crops in comparison with application of synthetic $\mathrm{N}$ fertilizers.

Co-evolved soil microbes can function together more efficiently due to their synergistic adaptations, in contrast to those from different habitats (Revillini et al. 2016). The diazotrophs consortium used in the present study was composed of four free-living isolates; only one of those (J7) was isolated from the fungal natural habitat (Jarrahdale, WA), and the remaining three isolates were from Shenton Park, WA (agricultural soil, not the natural habitat of A. occidentalis). An $\mathrm{N}_{2}$ fixation rate as high as $207 \mathrm{~kg} \cdot \mathrm{ha}^{-1} \cdot \mathrm{yr}^{-1}$ was estimated in restored bauxite mines in the jarrah forest ecosystem with high densities of fast-growing native legumes (Koch 1987), indicating a remarkable $\mathrm{N}_{2}$-fixing capacity of the native diazotrophs. Accordingly, future works should include more isolates from the natural habitats of $\mathrm{A}$. occidentalis within WA and explore the extent of their synergistic interactions with this native fungus in terms of biological $\mathrm{N}_{2}$ fixation and the plant fitness attributes.

The diazotroph isolates used in this study were identified as Arthrobacter sp. (SP5/SP12), Bacillus flexus (SP15), and Paraburkholderia bryophila (J7), all of which have been documented as free-living diazotrophic bacteria (Mongodin et al. 2006; Eberl and Vandamme 2016; Yousuf et al. 2017). Out of the four added diazotrophs, only two of them (SP5/ SP12; Arthrobacter isolates) had higher relative abundance in the corresponding treatments (i.e., diazotrophs and dual treatments) (Fig. 3c), suggesting an effective establishment of these two isolates compared to the other two isolates (SP15 and J7) that had the same relative abundance across treatments. The enhanced soil total $\mathrm{N}$ in the dual treatment (Fig. 2c) could also be partially attributed to the enhanced relative abundances of the SP5/SP12 isolates (Fig. 3c). Nonetheless, we should bear in mind that the relative abundance does not necessarily reflect the magnitude of $\mathrm{N}_{2}$-fixing activities of diazotrophs. Future research, therefore, should focus on the activity of nif genes to further elucidate the interactions between A. occidentalis and diazotrophs.

In our previous study (Kariman et al. 2020), the root AM colonization was not affected by the presence of $A$. occidentalis in wheat and barley plants grown under deficiency of all essential nutrients. In the present study, however, the addition of microbial inoculums (diazotrophs and A. occidentalis, alone or in combination) resulted in a significant reduction in AM colonization of wheat roots under severe $\mathrm{N}$ deficiency conditions. Root AM colonization of maize plants was shown to be negatively affected by the 
$\mathrm{N}_{2}$-fixing bacterium (Bacillus subtilis) due to exudation of unknown volatile antifungal compounds (Xiao et al. 2008); hence, the decline in AM colonization of wheat plants in the present study could be due to antifungal properties of the added diazotrophic isolates. The decline in root AM colonization of plants inoculated only with $A$. occidentalis (compared to the control) can be possibly due to partial C allocation to the introduced FM fungus, leading to reduced $\mathrm{C}$ allocation to the indigenous AM fungi accompanied by decreased root colonization.

In our in vitro $C$ source utilization test (Table 2), $A$. occidentalis did not grow on lignocellulosic substrates, and could only grow on media supplemented with glucose or fructose, as well as wheat straw, which also contains large amounts of glucose along with cellulose, hemicellulose, and lignin as the main components (Collins et al. 2014). This trophic habit of A. occidentalis is similar to most ECM fungi, which are weak saprotrophs and utilize only hexoses as a food source (Smith and Read 2008; Parrent et al. 2009), suggesting a close phylogenetic/functional relationships between the FM fungus and ECM fungi. Similar to the majority of ECM fungi, $A$. occidentalis could not utilize sucrose (a disaccharide) as a food source (Table 2); there are only a few ECM species such as the black truffle (Tuber melanosporum) that possess invertase enzyme to hydrolyze sucrose (Martin et al. 2010). The fungal species closely related to A. occidentalis (i.e., those within the Boletaceae family) form ECM associations with host plants (Orlovich and Cairney 2004; Smith et al. 2013; Vasco Palacios 2016); hence, these trophic similarities between the FM fungus and ECM fungi are expected. Many ECM fungi have lost the capacity to decompose complex organic materials (i.e., lacking many lignocellulose-degrading enzymes) during their transition from saprotrophy to biotrophy (Kohler et al. 2015; Fesel and Zuccaro 2016). Organic matter decomposition activity of ECM fungi comprises primarily biochemical pathways (via diverse hydrolytic and oxidative enzymes) in response to nutrient limitation, i.e., it is a nutrient-scavenging function rather than an organic matter-degradation strategy to gain the energy source (Shah et al. 2016; Zak et al. 2019). Accordingly, nearly all ECM fungi seem to be solely dependent on living host plants as a food source (in form of hexoses), which also seems to be a plausible scenario for the FM fungus A. occidentalis, bearing in mind that its saprotrophic activity is limited to hexoses (Table 2). A BLAST search against the A. occidentalis draft genome sequence (Kariman et al. unpublished) confirmed that the invertase gene is absent in A. occidentalis. Interestingly, a sole dependence on the host plant as a food source has not hindered the persistence of the plant-fungus symbioses throughout evolution, with the persistence of the 460 million-year-old AM symbiosis (Redecker et al. 2000).

\section{Conclusions}

The FM fungus A. occidentalis, alone or in combination with diazotrophs, significantly improved the shoot and root biomass and nutrition (e.g., N, P, K, Zn, Fe) of wheat plants grown under $\mathrm{N}$ deficiency, which can be attributed to the synergistic interactions between A. occidentalis and indigenous or added diazotrophs. The presence of A. occidentalis led to modification of the soil microbial composition while preserving the microbial species richness. The FM fungus was only able to utilize hexoses (glucose and fructose) in vitro, but it did not grow on media supplemented with sucrose or lignocellulosic substrates, thus displaying trophic traits similar to ECM fungi. Our results pave the way for future research on FM-diazotroph interactions that may have practical implications in improving $\mathrm{N}$ nutrition of agricultural crops in low- $\mathrm{N}$ and low-P conditions in an environmentally friendly manner.

Supplementary Information The online version contains supplementary material available at https://doi.org/10.1007/s00374-021-01616-7.

Funding Open Access funding enabled and organized by CAUL and its Member Institutions. This study was supported by research funds provided by the Grains Research and Development Corporation (GRDC; project code: UWA1904-005RTX) and the University of Western Australia (UWA).

\section{Declarations}

Competing interests The authors declare no competing interests.

Open Access This article is licensed under a Creative Commons Attribution 4.0 International License, which permits use, sharing, adaptation, distribution and reproduction in any medium or format, as long as you give appropriate credit to the original author(s) and the source, provide a link to the Creative Commons licence, and indicate if changes were made. The images or other third party material in this article are included in the article's Creative Commons licence, unless indicated otherwise in a credit line to the material. If material is not included in the article's Creative Commons licence and your intended use is not permitted by statutory regulation or exceeds the permitted use, you will need to obtain permission directly from the copyright holder. To view a copy of this licence, visit http://creativecommons.org/licenses/by/4.0/.

\section{References}

Abd-Alla MH, El-Enany AWE, Nafady NA, Khalaf DM, Morsy FM (2014) Synergistic interaction of Rhizobium leguminosarum bv. viciae and arbuscular mycorrhizal fungi as a plant growth promoting biofertilizers for faba bean (Vicia faba L.) in alkaline soil. 
Microbiol Res 169:49-58. https://doi.org/10.1016/j.micres.2013. 07.007

Backer R, Rokem JS, Ilangumaran G, Lamont J, Praslickova D, Ricci E, Subramanian S, Smith D (2018) Plant growth-promoting Rhizobacteria: context, mechanisms of action, and roadmap to commercialization of biostimulants for sustainable agriculture. Front Plant Sci 1473https://doi.org/10.3389/FPLS.2018.01473

Berman-Frank I, Lundgren P, Falkowski P (2003) Nitrogen fixation and photosynthetic oxygen evolution in cyanobacteria. Res Microbiol 154:157-164

Bolyen E, Rideout JR, Dillon MR, Bokulich NA, Abnet CC et al (2019) Reproducible, interactive, scalable and extensible microbiome data science using QIIME 2. Nat Biotechnol 37:852-857

Cenis JL (1992) Rapid extraction of fungal DNA for PCR amplification. Nucleic Acids Res 20:2380

Clarke K (1993) Non-parametric multivariate analyses of changes in community structure. Aust J Ecology 18:117-143

Collins SR, Wellner N, Martinez Bordonado I, Harper AL, Miller CN, Bancroft I, Waldron KW (2014) Variation in the chemical composition of wheat straw: the role of tissue ratio and composition. Biotechnol Biofuels 7:1-14. https://doi.org/10.1186/ s13068-014-0121-y

Courty PE, Buee M, Diedhiou AG, Frey-Klett P, Tacon FL, Rineau F, Turpault MP, Uroz S, Garbaye J (2010) The role of ectomycorrhizal communities in forest ecosystem processes: new perspectives and emerging concepts. Soil Biol Biochem 42:679-698

Dellagi A, Quillere I, Hirel B (2020) Beneficial soil-borne bacteria and fungi: a promising way to improve plant nitrogen acquisition. J Exp Bot 71:4469-4479

Eberl L, Vandamme P (2016) Members of the genus Burkholderia: good and bad guys [version 1; referees: 3 approved]. F1000Research 5

Eickhout B, Bouwman AF, van Zeijts H (2006) The role of nitrogen in world food production and environmental sustainability. Agric Ecosyst Environ 116:4-14. https://doi.org/10.1016/J.AGEE.2006. 03.009

FAOSTAT (2019) World fertilizer trends and outlook to 2022

Fesel PH, Zuccaro A (2016) Dissecting endophytic lifestyle along the parasitism/mutualism continuum in Arabidopsis. Curr Opin Microbiol 32:103-112

Galloway N, Schlesinger WH, Ii HL, Michaels A, Schnoor JL (1995) Nitrogen fixation : anthropogenic enhancement-environmental response reactive $\mathrm{N}$, providing activities have resulted in the fixation of an additional $\mathrm{Tg} \mathrm{N}$ yr '•), fertilizer production $\mathrm{Tg} \mathrm{N}$ yr '•), and cultivation of crops (e.g., remaining $80 \mathrm{Tg} \mathrm{N}$ yr. Global Biogeochem Cycles 9:235-252

Giovannetti M, Mosse B (1980) An evaluation of techniques for measuring vesicular arbuscular mycorrhizal infection in roots. New Phytol 489-500

Hug LA, Baker BJ, Anantharaman K, Brown CT, Probst AJ, Castelle CJ, Butterfield CN, Hernsdorf AW, Amano Y, Ise K, Suzuki Y, Dudek N, Relman DA, Finstad KM, Amundson R, Thomas BC, Banfield JF (2016) A new view of the tree of life. Nat Microbiol $1: 1-6$

James EK (2000) Nitrogen fixation in endophytic and associative symbiosis. F Crop Res 65:197-209. https://doi.org/10.1016/S03784290(99)00087-8

Joergensen RG, Brookes PC (1990) Ninhydrin-reactive nitrogen measurements of microbial biomass in $0.5 \mathrm{M} \mathrm{K} 2 \mathrm{SO} 4$ soil extracts. Soil Biol Biochem 22:1023-1027

Kariman K, Barker SJ, Finnegan PM, Tibbett M (2012) Dual mycorrhizal associations of jarrah (Eucalyptus marginata) in a nurse-pot system. Aust J Bot 60:661-668

Kariman K, Barker SJ, Jost R, Finnegan PM, Tibbett M (2014) A novel plant-fungus symbiosis benefits the host without forming mycorrhizal structures. New Phytol 201:1413-1422
Kariman K, Barker SJ, Tibbett M (2018) Structural plasticity in rootfungal symbioses: diverse interactions lead to improved plant fitness. PeerJ 6:e6030

Kariman K, Scanlan C, Boitt G, Rengel Z (2020) Feremycorrhizal symbiosis confers growth and nutritional benefits to mycorrhizal and non-mycorrhizal crops. Soil Biol Biochem 151:108060

Koch J (1987) Nitrogen accumulation in a rehabilitated bauxite mined area in the Darling Range, Western Australia. Aust for Res 17:59-72

Kohler A, Kuo A, Nagy LG et al (2015) Convergent losses of decay mechanisms and rapid turnover of symbiosis genes in mycorrhizal mutualists. Nat Genet 47:410-415. https://doi.org/10.1038/ ng. 3223

Lambilliotte R, Cooke R, Samson D, Fizames C, Gaymard F, Plassard C, Tatry MV, Berger C, Laudié M, Legeai F, Karsenty E, Delseny M, Zimmermann S, Sentenac H (2004) Large-scale identification of genes in the fungus Hebeloma cylindrosporum paves the way to molecular analyses of ectomycorrhizal symbiosis. New Phytol 164:505-513

Letunic I, Bork P (2019) Interactive Tree Of Life (iTOL) v4: recent updates and new developments. Nucleic Acids Res 47:W256-W259

Liu Z, Lozupone C, Hamady M, Bushman FD, Knight R (2007) Short pyrosequencing reads suffice for accurate microbial community analysis. Nucleic Acids Res 35:e120

Martin F, Kohler A, Murat C et al (2010) Périgord black truffle genome uncovers evolutionary origins and mechanisms of symbiosis. Nature 464:1033-1038. https://doi.org/10.1038/ nature 08867

Matsen FA, Kodner RB, Armbrust EV (2010) pplacer: linear time maximum-likelihood and Bayesian phylogenetic placement of sequences onto a fixed reference tree. BMC Bioinformatics 11:1-16

Mongodin EF, Shapir N, Daugherty SC, DeBoy RT, Emerson JB, Shvartzbeyn A, Radune D, Vamathevan J, Riggs F, Grinberg V, Khouri H, Wackett LP, Nelson KE, Sadowsky MJ (2006) Secrets of soil survival revealed by the genome sequence of Arthrobacter aurescens TC1. PLoS Genet 2:2094-2106. https:// doi.org/10.1371/journal.pgen.0020214

Mus F, Crook MB, Garcia K, Costas AG, Geddes BA, Kouri ED, Paramasivan P, Ryu MH, Oldroyd GED 5, Poole PS, Udvardi MK, Voigt CA, Ané JM7, Peters JW (2016) Symbiotic nitrogen fixation and the challenges to its extension to nonlegumes. Appl Environ Microbiol 82:3698-3710

Oksanen J, Blanchet FG, Friendly M et al (2019) (2019) vegan: Community Ecology Package. R Package Version 2:5-6

Olsson PA, Wallander H (1998) Interactions between ectomycorrhizal fungi and the bacterial community in soils amended with various primary minerals. FEMS Microbiol Ecol 27:195-205. https://doi.org/10.1111/j.1574-6941.1998.tb00537.x

Orlovich DA, Cairney JG (2004) Ectomycorrhizal fungi in New Zealand: current perspectives and future directions. New Zeal J Bot 42:721-738

Parrent JL, James TY, Vasaitis R, Taylor AFS (2009) Friend or foe? Evolutionary history of glycoside hydrolase family 32 genes encoding for sucrolytic activity in fungi and its implications for plant-fungal symbioses. BMC Evol Biol 9:1-16. https://doi.org/ 10.1186/1471-2148-9-148

Paul LR, Chapman BK, Chanway CP (2007) Nitrogen fixation associated with Suillus tomentosus tuberculate ectomycorrhizae on Pinus contorta var. latifolia. Ann Bot 99:1101-1109. https:// doi.org/10.1093/aob/mcm061

Püschel D, Janoušková M, Voříšková A, Gryndlerova H, Vosatka M, Jansa J (2017) Arbuscular mycorrhiza stimulates biological nitrogen fixation in two Medicago spp. through improved 
phosphorus acquisition. Front Plant Sci 8:390. https://doi.org/ 10.3389/fpls.2017.00390

Rayment GE, Lyons DJ (2011) Soil chemical methods: Australasia. CSIRO publishing

Redecker D, Kodner R, Graham LE (2000) Glomalean fungi from the Ordovician. Science (80- ) 289:1920-1921. https://doi.org/ $10.1126 /$ science. 289.5486 .1920

Reuter D, Robinson JB (1997) Plant analysis: an interpretation manual. CSIRO publishing, Melbourne, Australia

Revillini D, Gehring CA, Johnson NC (2016) The role of locally adapted mycorrhizas and rhizobacteria in plant-soil feedback systems. Funct Ecol 30:1086-1098. https://doi.org/10.1111/ $1365-2435.12668$

Sabannavar SJ, Lakshman HC (2008) Interactions between Azotobacter, Pseudomonas and arbuscular mycorrhizal fungi on two varieties of Sesamum indicum L. J Agron Crop Sci 194:470-478

Shah F, Nicolás C, Bentzer J, Ellström M, Smits M, Rineau F, Canbäck B, Floudas D, Carleer R, Lackner G, Braesel J, Hoffmeister D, Henrissat B, Ahrén D, Johansson T, Hibbett DS, Martin F, Persson P, Tunlid A (2016) Ectomycorrhizal fungi decompose soil organic matter using oxidative mechanisms adapted from saprotrophic ancestors. New Phytol 209:1705-1719. https://doi.org/ 10.1111/nph.13722

Smith ME, Henkel TW, Uehling JK, Fremier AK, Clarke HD, Vilgalys R (2013) The ectomycorrhizal fungal community in a neotropical forest dominated by the endemic dipterocarp Pakaraimaea dipterocarpacea. PLoS One 8:e55160

Smith SE, Read DJ (2008) Mycorrhizal symbiosis. Academic press, London
Vasco Palacios AM (2016) Ectomycorrhizal fungi in Amazonian tropical forests in Colombia. Utrecht University, Utrecht, The Netherlands

Wickham H, Chang W, Henry L, et al (2020) ggplot2: create elegant data visualisations using the grammar of graphics; R package version 3.3. $0 ; 2020$

Xiao X, Chen H, Chen H, Wang J, Ren C, Wu L (2008) Impact of Bacillus subtilis JA, a biocontrol strain of fungal plant pathogens, on arbuscular mycorrhiza formation in Zea mays. World J Microbiol Biotechnol 24:1133-1137

Yousuf J, Thajudeen J, Rahiman M, Krishnankutty S, Alikunj AP, Abdulla MH (2017) Nitrogen fixing potential of various heterotrophic Bacillus strains from a tropical estuary and adjacent coastal regions. J Basic Microbiol 57:922-932. https://doi.org/ 10.1002/jobm.201700072

Zak DR, Pellitier PT, Argiroff WA, Castillo B, James TY, Nave LE, Averill C, Beidler KV, Bhatnagar J, Blesh J, Classen AT, Craig M, Fernandez CW, Gundersen P, Johansen R, Koide RT, Lilleskov EA, Lindahl BD, Nadelhoffer KJ, Phillips RP, Tunlid A (2019) Exploring the role of ectomycorrhizal fungi in soil carbon dynamics. New Phytol 223:33-39. https://doi.org/10.1111/nph.15679

Publisher's Note Springer Nature remains neutral with regard to jurisdictional claims in published maps and institutional affiliations. 